Dept. of Physiology,

Fac. Vet. Medicine, Cairo University.

\title{
BIOCHEMICAL STUDIES ON IONIC HOMEOSTASIS IN DIABETIC AND INSULIN-TREATED ALBINO RATS
}

(With 2 Tables)

By

\author{
K.A. ATTIA and SAFAA S. ABD EL-HAMID*
}

* Dept. of Biochemistry and Food deficiency, Animal Health Institute, Dokki.

(Received at 29/12/2005)

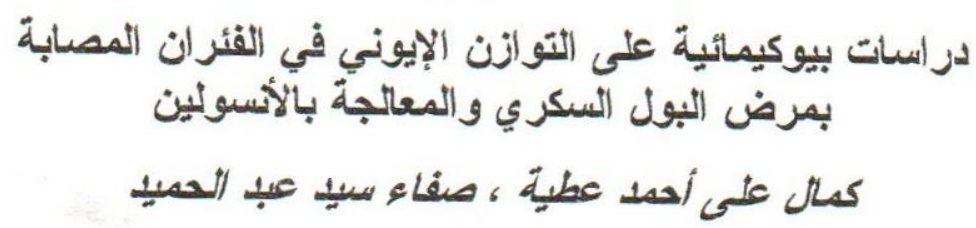

تهدف الدراسة لفحص أنزان أيونات النحاس و الماغنسيوم و الكالسيوم و الصوديوم و البوتأسيوم

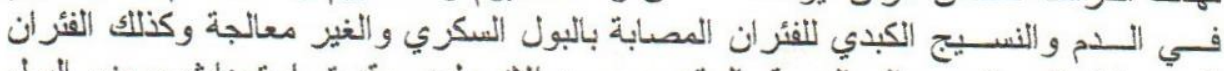

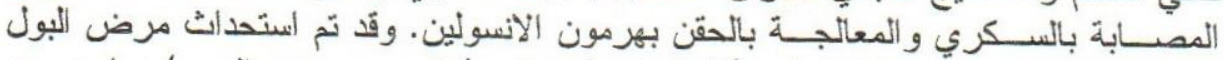

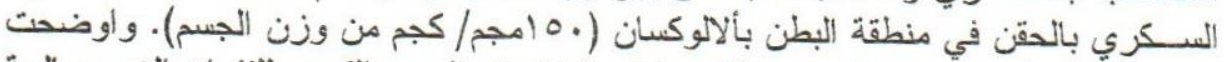

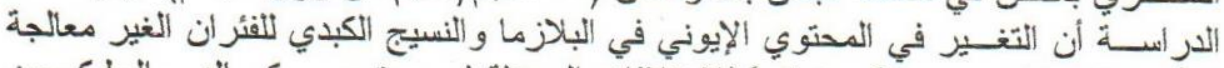

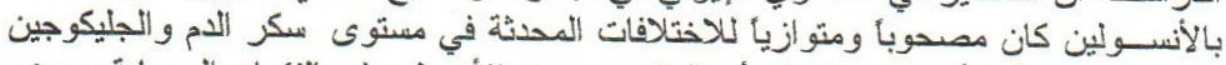

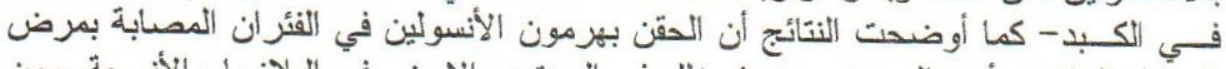

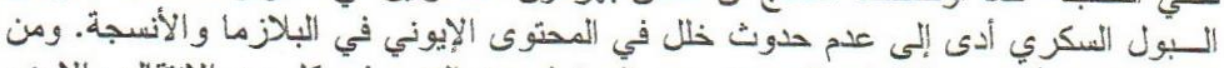

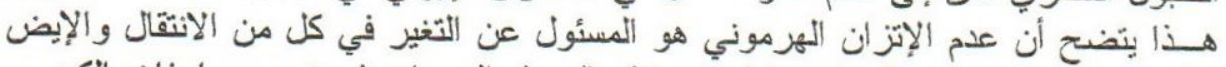

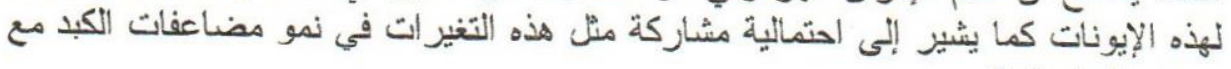
مرض البول السكري.

\section{SUMMARY}

In the present study, copper, magnesium, calcium, sodium and potassium homeostasis as well as blood glucose and liver glycogen were investigated in untreated and treated diabetic rats. The ionic alterations in plasma and liver were concomittant with those fluctuations occurring in blood glucose and liver glycogen through all the periods of investigation. In treated rats, insulin injection was able to maintain, for a large extent, the ionic homeostasis. It seems that the endocrine imbalance was responsible for the alterations in both transport and metabolism of those ions. Also, it is possible that alterations in plasma and tissue levels of those ions may contribute to the development of liver complication. 
Key words: Diabetic, Insulin, Homeostasis

\section{INTRODUCTION}

Diabetes Mellitus was proved to increase carrier-mediated glucose uptake both in vivo and in vitro (Debnam et al., 1988). It also produces an increase in degradation of ATP-ase by a mechanism which is not clear, but there is a possibility that it is caused by alterations induced by diabetes in lysosomes that are autopathy associated with hepatic autophagy (Jorda et al., 2001).

Copper deficient rats exhibit a decrease in the desastrous activity of liver microsomes (Oveka et al., 1988). Daily loss of copper is significantly increased within two days after induction of the diabetic condition (Failla, 1983), in addition to altered calcium and potassium metabolism (Failla and Kiser, 1983).

Both insulin and non-insulin dependent diabetic patients have been reported to have altered sodium (Weidmann and Ferrari, 1991) and magnesium metabolism (Sjogren and Nilsson, 2003). The total intracellular ionic strength displays an age - dependent increase due mainly to increase of intracellular potassium and sodium concentrations in postmitotic cells (Semsei and Nagy, 1984).

The present study investigates the effect of experimentally induced diabetes mellitus on the ionic homeostasis in plasma and liver tissue. Also, the effect of insulin treatment was clarified.

\section{MATERIALS and METHODS}

Seventy five adult male albino rats were used in this study. Their body weight ranged from $150-170 \mathrm{mg}$. They were acclimatized in the laboratory for one week. Ten rats were kept as control (normal) group. The remaining 65 rats were used as diabetic group where each rat was injected intraperitoneolly with alloxan (Houses LTD, British Drug), $150 \mathrm{mg} / \mathrm{kg}$ body weight dissolved into $0.2 \mathrm{ml}$ distilled water. The control rats were injected by distilled water under the same conditions.

After induction of diabetes, rats were subdivided into two experimental groups; diabetic untreated (40 rats) and diabetic treated group ( 25 rats). Each rat of the diabetic treated group was injected S/C with a daily dose of insulin (Nilab Retard, NPH, NOVO Nordisk, ALS2880, Bagsvaerd, Denmark) equal to one unit / rat, contained in $0.1 \mathrm{ml}$ distilled water for 60 successive days. Rats of normal and diabetic untreated groups were injected with distilled water for the same duration. All rats were kept under hygienic conditions and fed on a 
balanced ration. The drinking water and food were provided adlibitum throughout the experiment.

\section{Sampling and measurements:}

Ten blood samples were collected from rats of the experimental groups (diabetic untreated and diabetic treated groups) at 15,30, 45 and 60 days of the experiment for preparation of serum and plasma. Also, at each time interval, five rats from each group were scarified and liver speciemens were collected. Ten blood samples (plasmas \& serum) and five liver speciemens were also collected from rats of control group.

Blood and liver speciemens were used for determination of copper, magnesium, calcium, sodium and potassium ions. Blood glucose level (Cooper and Daniel, 1970) and liver glycogen content (Seifter et al., 1950) were also analyzed. Serum and hepatic copper concentrations were determined by pathocuprion following deproteinization according to the method of Zak (1958) using a commercial kits obtained from Bohringer Mannheima. Magnesium content was estimated in plasma and liver tissues according to the method of Mann and Joe (1956). Calcium was estimated in plasma and liver according to Barnett et al., (1973). The colorimeteric method of Trinder (1951) was used to determine the sodium concentration of plasma and hepatic tissue. Potassium was measured in the protein free filterate colorimetrically according to Sunderman and Sunderman (1958).

Statistical analysis of data was done using analysis of variance testing considering a significance of probability $<.0 .05$ (Snedecar and Cochrane, 1980).

\section{RESULTS}

Table (1) shows that, in diabetic untreated rats, blood glucose level was significantly elevated allover the experimental times after induction of diabetes (12hrs. after alloxan injection). In comparison with the control data, serum copper level was significantly increased in all diabetic stages, while the levels of plasma calcium, potassium and magnesium were significantly decreased at 15 days, then showing a steadily non-significant increase during the other stages of the experiment. On the other hand, in diabetic treated rats, the blood levels of glucose and after ions were comparable with that of control rats.

Table (2) indicates that, in diabetic untreated rats, the contents of liver glycogen was significantly increased allover the diabetic stages comparing with its level in the liver of control rats. The levels of liver copper and calcium were significantly increased allover the experimental times. Magnesium content of the liver was significantly decreased 
during all periods of the experiment. However, sodium and potassium contents were recorded to be significantly increased at 15 days of the experiment, then showed a non- significant steadily decrease during the other periods of the experiment. On the other hand, in diabetic treated rats, a non - significant alterations in the liver contents of glycogen and other measured ions were recorded.

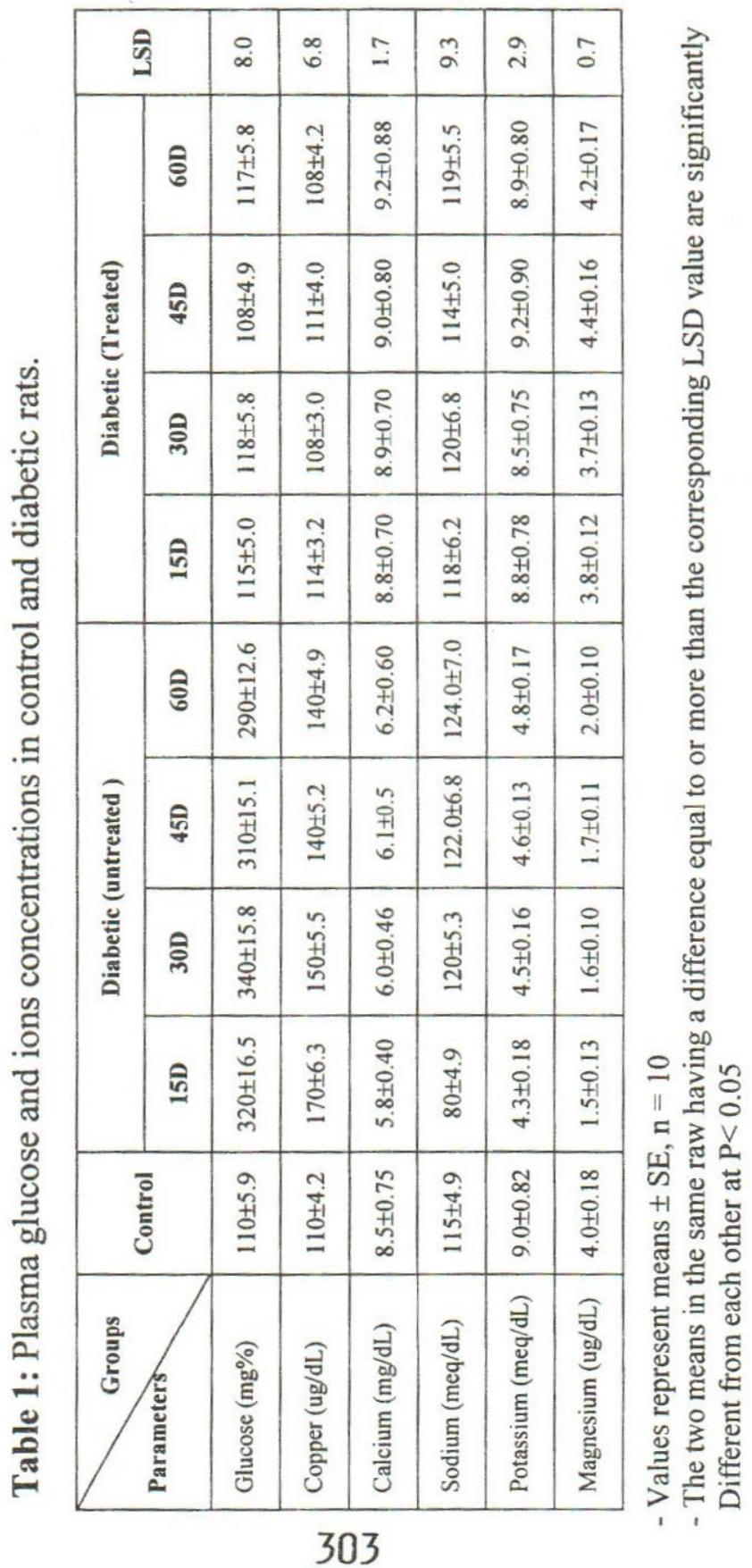


Assiut Vet. Med. J. Vol. 52 No. 108 January 2006

\begin{tabular}{|c|c|c|c|c|c|c|c|c|}
\hline \multicolumn{2}{|c|}{ की } & ஸి & $=$ & $\stackrel{-}{0}$ & $\begin{array}{l}\text { ก̇ } \\
\text { O }\end{array}$ & $\frac{O}{\dot{\sigma}}$ & $\frac{\circ}{i}$ & 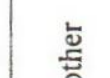 \\
\hline \multirow{4}{*}{ 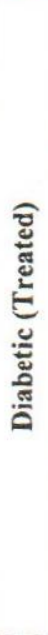 } & క్ & 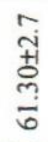 & 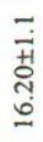 & $\begin{array}{l}\infty \\
0 \\
0 \\
+1 \\
+ \\
+\end{array}$ & 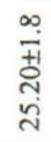 & $\begin{array}{l}+ \\
\text { 풍 } \\
\text { ते }\end{array}$ & 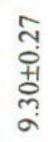 & 足 \\
\hline & ซิ & $\begin{array}{l}\tilde{i} \\
\text { ț } \\
\dot{0}\end{array}$ & 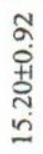 & $\begin{array}{l}\text { 웅 } \\
0 \\
+1 \\
\infty \\
+\end{array}$ & 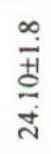 & $\frac{\frac{a}{1+}}{\frac{0}{8}}$ & $\begin{array}{l}\text { సे } \\
\text { †े } \\
\text { ¿े } \\
\infty\end{array}$ & 壱 \\
\hline & 今్ & 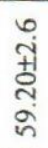 & 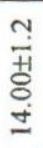 & $\begin{array}{l}\infty \\
\stackrel{\infty}{+} \\
+ \\
+ \\
+\end{array}$ & $\begin{array}{l}\frac{n}{+1} \\
\frac{1}{0} \\
\dot{n}\end{array}$ & 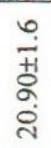 & $\begin{array}{l}0 \\
\text { o } \\
\text { +1 } \\
\text { +1 } \\
\text { aे }\end{array}$ & 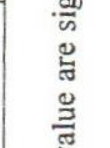 \\
\hline & 은 & तิ & 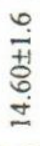 & $\begin{array}{l}\infty \\
\text { ஸे } \\
\text { +1 } \\
8 \\
\text { n. }\end{array}$ & 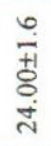 & $\begin{array}{l}n \\
\text { +1 } \\
\infty \\
0 \\
0\end{array}$ & $\begin{array}{l}\text { స̃ } \\
0 \\
+ \\
\infty \\
\infty \\
\infty\end{array}$ & 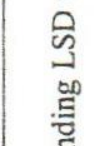 \\
\hline \multirow{4}{*}{ 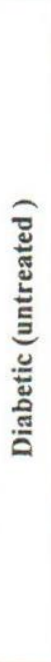 } & 응 & 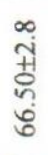 & 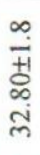 & 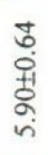 & $\frac{\frac{N}{d}}{\frac{d}{d}}$ & 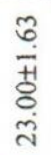 & $\begin{array}{l}= \\
0 \\
+1 \\
0 \\
0 \\
0\end{array}$ & 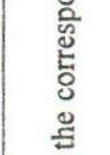 \\
\hline & ซิ & $\begin{array}{l}0 \\
\text { in } \\
\text { 음 } \\
\stackrel{0}{\circ}\end{array}$ & 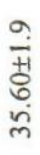 & $\begin{array}{l}8 \\
0 \\
+1 \\
\infty \\
\text { i }\end{array}$ & $\frac{n}{\frac{n}{0}}$ & $\begin{array}{l}\text { 品 } \\
\text { 菅 } \\
\dot{\sim}\end{array}$ & $\begin{array}{l}\infty \\
\text { o } \\
\text { ஸे } \\
\text { ஸู }\end{array}$ & 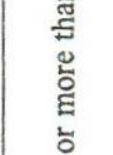 \\
\hline & ిิ & 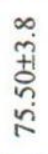 & 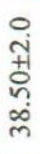 & $\begin{array}{l}\text { N } \\
0 \\
+1 \\
8 \\
0\end{array}$ & $\frac{9}{\frac{9}{0}}$ & $\begin{array}{l}\text { I } \\
\text { के } \\
\text { ¿े }\end{array}$ & $\begin{array}{l}0 \\
0 \\
+1 \\
0 \\
0 \\
0\end{array}$ & 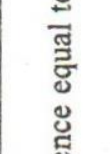 \\
\hline & ถิ & $\begin{array}{l}0 \\
\stackrel{+}{+} \\
\text { t艹 } \\
\stackrel{0}{0} \\
\stackrel{\infty}{\infty}\end{array}$ & 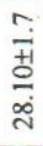 & 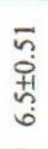 & $\begin{array}{l}3 \\
\text { +1 } \\
\text { o } \\
\text { m }\end{array}$ & $\frac{\infty}{\dot{\pi}}$ & $\begin{array}{l}m \\
0 \\
+1 \\
0 \\
\text { n. }\end{array}$ & 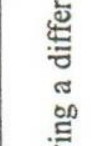 \\
\hline \multicolumn{2}{|c|}{ 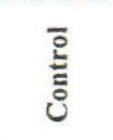 } & $\begin{array}{l}0 \\
\text { Tे } \\
\text { ठ }\end{array}$ & 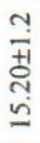 & 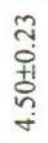 & $\frac{N}{\frac{N}{+1}}$ & 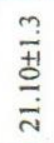 & $\begin{array}{l}m \\
0 \\
+1 \\
\frac{1}{0} \\
a\end{array}$ & 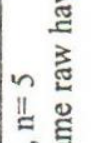 \\
\hline \multicolumn{2}{|c|}{ 亭 } & 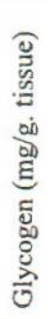 & 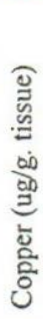 & 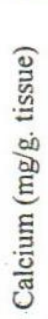 & 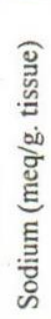 & 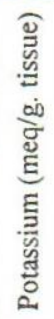 & 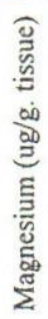 & 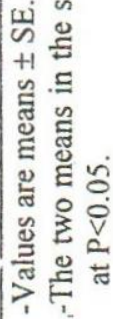 \\
\hline
\end{tabular}




\section{DISCUSSION}

Data of the present study showed that the levels of glucose in diabetic untreated rats were steadily increased with the progress of time and then decreased but still higher than that of the control or diabetic treated rats (Table 1). Debnam and Ebrahim (1989) reported that insulin stimulation of glucose uptake (in vivo) in diabetic intestine involves events at the brush border membrane. The mechanisms include an increased surface area for uptake and enhanced transmembrane electrical gradient. The later will have a major effect on the transport of other substances when the uptake pathway is primarily $\mathrm{Na}^{+}$dependent. In vitro, insulin was found to stimulate glucose uptake. The enhancement at the brush border is involved and the mechanisms include an increased surface area for uptake and an electrical gradient. This conclusion agrees well with that of previous study (Hopfer, 2000) which suggested that changes in the $\mathrm{Na}^{+}$conductance of the brush boarder membrane may result in an increase in the electrochemical gradient $\mathrm{g} \mathrm{Na}^{+}$across the brush border membrane in diabetic rats (Debnam et al., 1988).

Also, the obtained data revealed that the glycogen disturbances in diabetic untreated rats were higher than that of control or diabetic treated rats. Chatila and West (1996) reported that during periods of hyperglycemia glucose freely enters the hepatocytes driving glycogen synthesis, which was augmented further by adminstration of insulin to supra- physiological levels.

The accumulation of excessive amount of glycogen in the liver of diabetic untreated rats might be a function of intermittent episodes of hyperglycemia and hypoglycemia. The authers added such abnormalities are readly reversible with sustained euglycemic control and this is a state of insulin resistant rather than glycemic control.

In diabetic untreated rats serum and hepatic copper contents were significantly elevated in comparison with control or diabetic treated rats. Kryska and Kiczka (2002) reported that in hepatic disorders, the serum copper concentration is usually elevated. This may be caused either by necrosis of hepatocytes or disturbances in hepatic clearance. The deficiency of ceruloplasmin or its structural changes may also affect copper binding, moreover, Miniuk et al., (1989) mentioned that liver is the most important organ for copper homeostasis. At least 3 processes (played a decisive role for regular copper metabolism) take place in the preparation of copper elimination with bile, temporary storage of copper and incorporation of copper into ceruloplasmin. So, the increased copper 
conc. in both serum and hepatic tissue in diabetic untreated rats may be attributed to the imbalance between copper elimination, storage or incorporation that was associated with uncontrolled diabetes. Absence of such alterations in diabetic treated or control rats may augment such suggestion.

Magnesium contents of plasma and liver were significantly decreased allover diabetic stages. A poor intracellular magnesium concentration may result in defective tyrosine - kinase activity at the insulin receptor level and exaggerated intracellular calcium concentration. Both events are responsible for the impairment in insulin action and a worsening of insulin resistance in non- insulin dependent diabetic patients (Paolisso and Barbagalls, 1997). Moreover, in $\mathrm{Mg}^{+}$ deficiency, extracellular magnesium concentration is drastically reduced. Membrane permeability and turnover of $\mathrm{Na}^{+}, \mathrm{K}^{+}$and $\mathrm{Ca}^{2+}$ may be increased. Upon the increase of intracellular $\mathrm{Ca}^{2+}$ passive $\mathrm{K}^{+}$efflux is enhanced (Gunther 1986).

In the present study, plasma calcium levels were decreased in all periods investigation in diabetic untreated rats as compared to those of normal rats. The regulation of the concentration of cytosolic free calcium under conditions of limited ATP availability is of critical importance for cell survival (Brecht and Groot, 2003). The elevated levels of calcium activate a number of hydrolytic enzymes such phospholipase $A_{2}$ which in turn damage the cell membrane and associated structures (Sakaida et al., 1992). In contrast, current results indicated a significant increase in hepatic tissues allover the experimental periods in diabetic untreated rats as compared to those of diabetic treated or control rats. It has been previously reported that calcium elevation in hepatocytes was associated with constriction of pericanalicular microfilaments which might play a role in stimulating bile secretion (Watanabe \& Philips, 1984). Moreover, calcium metabolism was reported to be altered in diabetic patients as a sequence to increased $\mathrm{Ca}^{2+}$ excretion in the urine, decreased $\mathrm{Ca}^{2+}$ absorption in the intestine and reduced bone mass (Gallagher and Lambett, 1982).

The plasma $\mathrm{Na}^{+}$content was significantly decreased in diabetic untreated rats at 15 days of the experiment in comparison with those of diabetic treated or control rats, then a non- significant steadily increase in its level was observed allover the other experimental periods. O'Hare et al., (1985) reported that a significant increase of total exchangeable $\mathrm{Na}^{+}$in diabetic patients was associated. The increased filtered load of glucose in diabetes patients was associated. The increased filtered load 
of glucose in diabetes will, via activation of the sodium /glucose cotransported, stimulates proximal tubular $\mathrm{Na}^{+}, \mathrm{K}^{+}$Atpase activity and increased tubular sodium reabsorption (Korner et al., 1994). The glomerular lesions and hypertension may be related to the sodium retention induced by hyperglycoemia. In contrast to the plasma, the liver tissue content of sodium was increased then decreased again as compared with those of diabetic treated and control rats. Filed and Hirosa, (1966) attributed such changes to glucose - induced osmotic diuresis. Initially these are losses of water, $\mathrm{Na}^{+}$and chloride from the extracellular fluid but in continuation, loss also occurs from the intracellular component. Debnam et al. (1988) attributed the flactuation in plasma $\mathrm{Na}^{+}$contents to the increased transport mediated via an altered electrochemical gradient for $\mathrm{Co}-$ Transport of $\mathrm{Na}^{+}$across the brush border membrane.

Plasma content of $\mathrm{K}^{+}$was significantly decreased in diabetic untreated rats in comparison with diabetic treated and control rats. It is well established that stimulatory glucose concentrations induce a decrease in $\mathrm{K}^{+}$conductance because of the closure of $\mathrm{K}$ - Atpase channels. Moreover, liver $\mathrm{K}^{+}$contents were significantly increased at 15 days then slightly decreased during the other experimental periods. Haddad et al., (1991) reported that the swelling of hepatocytes induced by hypotonic media is associated with an increase in $\mathrm{K}^{+}$conductance, consistent with opening of $\mathrm{K}^{+}$channels. The ensuring efflux of electrolytes and water through these channels is thought to decrease hepatocellular volume toward basol values (Lidofsky and Roman, 1997).

The results suggest that the endocrine imbalance associated with diabetes was responsible for the alterations of transport and metabolism of the studied ions. Also the results point out the possibility that alterations in plasma \& tissue levels of those ions contribute to the development of liver complications associated with long - term diabetes. Insulin treatment was also able to correct the ionic imbalance occured in
diabetes.

\section{REFERENCES}

Barnett, R.N.; Shodon, S.B. and Goldberg, M.H.(1973): Performace of kits used for clinical chemical analysis of Calcium in serum. Am. J. Clin. Pathol. 59: 836-9.

Brecht, M.; and Groot, H. (2003): Improvement of the energy status of hypoxic hepatocytes by calcium channel blockers. Res. Commun. Chem. Pathol. Pharmacol. 82:185-98. 
Chatila, R. and West, A.B. (1996): Hepatomegaly and abnormal tests due to glycogenesis in adults with diabetes. Medicine 75/6:327323.

Cooper, G.R. and Danial, M.C. (1970): Colorimetirc determination of glucose. Clin. Chem. 6: 159-165.

Debnam, E.S. and Ebrahim, H.Y. (1989): Diabetes mellitus and the sodium electrochemical grdient membrane of rat intestinal enterocytes. J. Endocrinology 123: 453-59.

Debnam, S.E.; Karasov, H.W. and Thompson, S.C. (1988): Nutrient uptake by rat enterocytes during diabetes mellitus; Evidence for an increased sodium electrochemical gradient Physiol. 397: 503-12.

Failla, L.M. (1983): Trace element metabolism in the chemically diabetic rat. Biol. Trace Elem. Res. 5: 275-84.

Failla, M.L. and Kiser, R.A. (1983): Hepatic and renal metabolism of copper and zinc in the diabetic rats. Am. J. Physiol. 244: E 115-121.

Field, J. B. and Hirosa, (1966): Effects of ions on TSH stimulation of ${ }^{+32} \mathrm{P}$ incorporation into thyroid slice phospholipid Clin. Pathol. Serum Electroyte 6: 362-363.

Gallagher, J.C. and Lambett, P.W. (1982): Impaired calcium absorption with normal vitamin $D$ levels in Juvenile onset diabetes mellitus. Clin. Res. 30: 742-750.

Gunther, T. (1986): Magnesium: Cardio vascular biochemistry. Mag. Bull. 8: 136-139.

Haddad, P.; Beck, S.J.; Boyer, L.J. and Gral, J. (1991): Role of chloride ions in cell volume regulation. An. J. Physiol. 261: 48.

Hoipfer, U. (2000): Diabetes mellitus: changes in the transport properties of isolatad intestinal microvillus membranes. Endocrinol. 9: 329.

Jorda, A.; $k$ Perez- Pastor, E. and Portotes, M. (2001): Effect of streptozotocindiabtes on rat liver mitochondrial adenosinetriphosphatase turnover. Biochem. J. 251: 621-24.

Korner, A.; Eklof, A. C.; Celsi, G. and Aperia, A. (1994): Increased renal metabolism, in diabetes. Mechanism and functional implications. Diabetes 43: 629-33.

Kryska, A. and Kiczka, W. (2002): Zinc, Copper and magnesium in the serum of patients suffering from cirrhosis and chronic active hepatitis (in polish). Diagnost. Laboratoryjna 21: 233-35. 
Lidofsky, D.S. and Roman, M.R. (1997): Alanine uptake activates hepatocellular chloride channels. Am. J. Physiol. 273: G84953.

Mann, K.C. and Joe, H.J. (1956): Spectrophotometirc determination of magnesium with sodium 1- azo 2- hydroxy -3 (2,4 dimeththyl carbox anilido) norphothothalene-1 (2 hydroxy benzene - 5 sulfonate) Anal. Chem., 28: 202-205.

Miniuk, K.; Moniuszko Jakoniuk, J.; Kulikowska, E. and Omieljaniuk, N. (1989): The interactions of copper, lead and ethanol in rats: Effects on some biochemical parameters of blood. Pol. J. Pharmacol. Pharm., 41: 273-80.

Ohare, J.A.; Ferris, J.; Bradys D.J.; Twomey, B. and O Sullivan, D.J. (1985): Exchangeable Sodium and rennin in hypertensive diabetic patients with and without nephropathy. Hypertension 7 [Suppl 2]: 43-48.

Oveka, D.G., Miller, G. and Mederos, M.D. (1988): Fatty acids of liver, cardiac and adipose tissues from copper - deficient rats. J. Nut. 118: 480-6.

Paoliss-O, G. and Barbagalls, M. (1997): Hypertension, diabetes mellitus and insulin resistance. The role of intracellular magnesium. Am. J. Hypertens. 10/3: 346-55.

Sakaida, L.; Thomas, P.A. and Farber, L.J. (1992): Phospholipid metabolism and intracellular $\mathrm{Ca}$ homeostasis in cultured rathepatocytes intoxicated with cyanide. Am. J. Physiol. 263: C 684-90.

Seifter, S.; Dayton, S.; Novic, B. and Muntuyler, E. (1950): Estimation of glycogen with anthor reagent. Arch. Biochem. 25: 191-200.

Semseil, I. and ZS. Nagy, I. (1984): Effects of ionic strength on the activity of superoxide dismutase in vitro. Arch. Gerontol. Geriater., 3: 287-293.

Sjogren, A. and Nilsson, A. (2003): Magnesium, potasium and zinc deficiency in subjects with type II diabetes mellitus. Acta. Med. Scand. 224: 461-5.

Snedecor, G.W. and Cochrane, W.G. (1980): Statistical methods, pp. 327-329. Iowa state univ. Press, Ames, Iowa.

Sunderman, F. WN. and Sunderman, F.W. (1958): Serum electrolytes. XXII. A rapid, reliable method for serum potassium using tetraphenylboron. Am. J. Clin. Pathol. 29: 95-103.

Trinder, $P$. (1951): Rapid method for the determination of sodium in serum. Analyst 76: 596-599. 
Watanabe, S. and Philips, M.J. (1984): causes active contraction of bile canaliculi: direct evidence from microinjection studies Proc. Natl. Acad. Sci. USA. 81: 6164-68.

Weidmann, P. and Ferrari, P. (1991): Central role of sodium in hypertension in diabetic subjects. Diabetes Care 14: 220-232.

Zak, B. (1958): Simple procedure for the single sample determination of serum copper and iron. Clin. Chem.. Acta. 3: 328-332. 